\title{
Effects of once-daily extended release quetiapine fumarate on patient-reported outcomes in patients with generalized anxiety disorder
}

This article was published in the following Dove Press journal:

Neuropsychiatric Disease and Treatment

10 July 2012

Number of times this article has been viewed

\author{
Jean Endicott ${ }^{1}$ \\ Henrik Svedsäter ${ }^{2}$ \\ Julie C Locklear ${ }^{2}$ \\ 'Department of Psychiatry, \\ Columbia University, New York, \\ NY; ${ }^{2}$ AstraZeneca Pharmaceuticals, \\ Wilmington, DE, USA
}

Background: We evaluated the effects of once-daily extended-release quetiapine fumarate (quetiapine $\mathrm{XR}$ ) on patient-reported outcomes in generalized anxiety disorder (GAD).

Methods: This is a report of a pooled analysis from three acute 8-week, randomized, placebocontrolled, fixed-dose $(50,150,300 \mathrm{mg} /$ day) studies and a 52 -week maintenance flexible dose (50-300 mg/day) study of quetiapine XR monotherapy in patients with GAD. Quality of Life Enjoyment and Satisfaction Questionnaire Short Form (Q-LES-Q-SF) percent maximum total scores (items 1-14), item 15 ("satisfaction with medication"), item 16 ("overall life satisfaction"), and Pittsburgh Sleep Quality Index (PSQI) global scores are reported. Sheehan Disability Scale (SDS) total scores were also assessed (maintenance study only).

Results: The acute studies showed significant improvements at week 8 in Q-LES-Q-SF percent maximum total score with quetiapine XR $150 \mathrm{mg} /$ day $(P<0.001)$ and item 16 with quetiapine XR $50(P<0.05)$ and $150 \mathrm{mg} /$ day $(P<0.001)$ versus placebo; PSQI global scores significantly improved with quetiapine XR 50, 150, and $300 \mathrm{mg}$ /day versus placebo $(P<0.001)$. The maintenance study showed significant benefits versus placebo with quetiapine $\mathrm{XR}$ 50-300 mg/day in Q-LES-Q-SF percent total score, item 15 and item 16 scores, PSQI global score, and SDS total score.

Conclusion: Quetiapine XR $150 \mathrm{mg}$ /day (acute studies) and 50-300 mg/day (maintenance study) improved quality of life, overall functioning, and sleep quality in patients with GAD.

Keywords: atypical antipsychotic, anxiety disorders, quality of life, sleep quality, functioning, randomized studies

\section{Introduction}

Generalized anxiety disorder (GAD) is one of the most persistent and common anxiety disorders among the general population, ${ }^{1}$ with community studies reporting 12 -month and lifetime prevalence rates of $3.0 \%$ and $5.0 \%$, respectively. ${ }^{2,3}$ Despite the availability of several treatment options, GAD remains a major public health concern and is among the leading causes of psychiatric morbidity in adults. ${ }^{4}$

GAD symptoms have a detrimental impact on patients' work, education, social environment, and health-related quality of life, ${ }^{5,6}$ and those affected often seek professional psychiatric help. ${ }^{4}$ Many patients continue to experience symptoms 6-12 years following diagnosis ${ }^{7}$ and fewer than $20 \%$ of patients achieve complete remission. ${ }^{8,9}$

Current first-line therapies for GAD include selective serotonin reuptake inhibitors and serotonin norepinephrine reuptake inhibitors. ${ }^{10}$ Significant improvement in quality of life and maintenance of functioning has been reported with both treatments; ${ }^{11,12}$ 
however, the utility of these agents may be compromised in some patients by their delayed onset of action (2-4 weeks). ${ }^{10}$ Sleep disturbance is a core symptom of GAD, with both the quality and quantity of sleep being adversely affected. The course of disturbed sleep in GAD is chronic but fluctuating, and is exacerbated by stressful events, although psychological treatments and/or some pharmacotherapeutic interventions can improve sleep quality to some extent. ${ }^{13}$ Rapid-acting benzodiazepines are often used as therapy adjunctive to selective serotonin reuptake inhibitors/serotonin norepinephrine reuptake inhibitors, resulting in prompt improvement in quality of sleep in patients with GAD. ${ }^{13}$ However, the efficacy of benzodiazepines is compromised by their decreased long-term effectiveness and tolerability issues. ${ }^{10}$

Immediate-release quetiapine fumarate improves the affective symptoms of schizophrenia ${ }^{14}$ and bipolar depression; ${ }^{15,16}$ studies have also shown improvement of anxiety symptoms when used as adjunctive therapy in patients with $\mathrm{GAD}^{17}$ and as acute monotherapy in patients with bipolar depression. ${ }^{15,16}$ A previous study reported improvements in quality of life and quality of sleep in patients with bipolar depression treated with immediate-release quetiapine. ${ }^{18}$ Extended-release quetiapine fumarate (quetiapine XR) is a once-daily formulation of quetiapine. ${ }^{19,20}$ Neither quetiapine nor quetiapine XR have regulatory approval for GAD in the United States or Europe.

Efficacy and tolerability results from the three Phase III studies of quetiapine XR monotherapy in adults (D1448C00009 [Titanium], ${ }^{21}$ D1448C00010 [Gold], ${ }^{22}$ and D1448C00011 [Silver] ${ }^{23}$ ), one acute study in an elderly population (D1448C00015 [Chromium $]^{24}$ ), and one longterm maintenance study in adults (D1448C00012 [Platinum $]^{25}$ ) have shown that quetiapine XR 50-300 mg/day is an effective and well tolerated treatment, with a tolerability profile similar to the known profile of quetiapine. In a pooled analysis of the adult acute monotherapy studies, significant improvements in total Hamilton Rating Scale for Anxiety (HAM-A) score at week 8 were observed for quetiapine XR $50 \mathrm{mg} /$ day (least squares mean [LSM] change $-13.31, P<0.001$ ), $150 \mathrm{mg} /$ day (LSM change -14.39 , $P<0.001$ ), and $300 \mathrm{mg}$ /day (LSM change -12.50 , $P<0.05$ ) versus placebo (LSM change -11.30$){ }^{26}$

Here we report an analysis of the effects of quetiapine XR on patient-reported outcomes in adult patients with GAD using pooled data from the three acute studies and the one long-term maintenance study.

\section{Materials and methods}

The designs and methodology of all four studies have been described previously, ${ }^{21-23,25}$ and the study details described here are intended as a brief summary only. All three acute studies were 8-week, multicenter, double-blind, randomized, parallel-group, placebo-controlled Phase III studies (D1448C00009 [Titanium], D1448C00010 [Gold], and D1448C00011 [Silver]).

The long-term maintenance study was a multicenter, double-blind, randomized, parallel-group, placebo-controlled Phase III study (D1448C00012 [Platinum]). It included an open-label run-in period (4-8 weeks of quetiapine XR), an open-label stabilization period (12-18 weeks of quetiapine XR), and a randomized withdrawal period (up to 52 weeks of randomized treatment with quetiapine XR or placebo).

\section{Inclusion criteria}

In brief, male and female outpatients, aged 18-65 years, with a Diagnostic and Statistical Manual of Mental Disorders, Fourth Edition, Text Revision (DSM-IV-TR) ${ }^{27}$ clinical diagnosis of GAD, confirmed by the Mini-International Neuropsychiatric Interview ${ }^{28}$ were eligible for inclusion in all four studies. In addition, to enter the randomized treatment period of the maintenance study, patients were required to have received $\geq 12$ weeks of quetiapine $\mathrm{XR} 50,150$, or $300 \mathrm{mg} /$ day during the stabilization period.

\section{Exclusion criteria}

Key exclusion criteria were: any other DSM-IV-TR Axis I disorder within 6 months of enrollment; DSM-IV-TR Axis II disorder that had a major impact on current psychiatric status; Montgomery Åsberg Depression Rating Scale item 10 score $\geq 4$ or a current serious suicidal or homicidal risk; an unstable medical condition, such as poorly controlled diabetes or unstable angina; or use of antipsychotic, mood stabilizer, or antidepressant drugs within 7 days prior to randomization.

\section{Acute studies}

The schedules for administration, uptitration, and discontinuation of study treatments are shown in Figure 1A. Studies D1448C00010 and D1448C00011 also included selective serotonin reuptake inhibitors as active controls (escitalopram $10 \mathrm{mg} /$ day and paroxetine $20 \mathrm{mg} /$ day, respectively); these data are not reported here because comparator drug arms were only included in the individual study analyses to allow for evaluation of assay sensitivity 
A

\begin{tabular}{|c|ccccccccc|}
\hline $\begin{array}{c}\text { Enrollment } \\
\text { phase }\end{array}$ & \multicolumn{4}{c|}{$\begin{array}{c}\text { Randomized } \\
\text { phase }\end{array}$} & \multicolumn{3}{c|}{$\begin{array}{c}\text { Post-treatment } \\
\text { follow-up }\end{array}$} \\
\cline { 1 - 5 }-28 to & Day & Day & Day & Day & Day & Day $6-56$ & Day & Day & Day \\
-1 day $^{\text {a }}$ & 1 & 2 & 3 & 4 & 5 & & 57 & 62 & 71
\end{tabular}

Quetiapine XR $50 \mathrm{mg} / \mathrm{day}^{\mathrm{b}}$

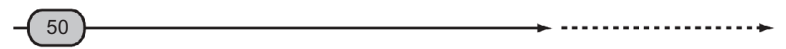

Quetiapine XR $150 \mathrm{mg} /$ day

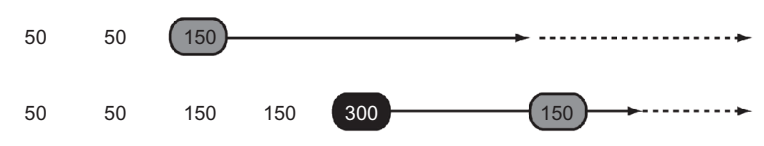

Quetiapine XR $300 \mathrm{mg} / \mathrm{day}^{\mathrm{c}}$

$10 \mathrm{mg} /$ day $^{d}$

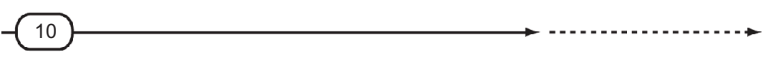

Paroxetine

$20 \mathrm{mg} / \mathrm{day}^{\mathrm{e}}$

Placebo . 
The Q-LES-Q-SF assessments were conducted at randomization and at weeks 4 and 8 in the acute studies, and at the start of the open-label run-in period, at randomization, and every 4 weeks thereafter until week 52 (or until discontinuation) in the maintenance study.

Sleep quality was assessed using change from randomization in the Pittsburgh Sleep Quality Index (PSQI) global score ${ }^{30}$ and the seven PSQI component scores of "sleep quality", "sleep latency", "sleep duration", "habitual sleep efficiency", "sleep disturbances", "use of sleep medication", and "daytime dysfunction". The PSQI assessments were conducted at randomization and at weeks 4 and 8 in the acute studies, and at the start of the open-label run-in period, at randomization, week 4, and every 12 weeks thereafter until week 52 (or until discontinuation) in the maintenance study.

In the maintenance study only, the ability to maintain level of functioning was assessed by change from randomization in the total Sheehan Disability Scale (SDS) score. ${ }^{31}$ The SDS includes three domains assessing "work/school", "social life", and "family life/home responsibilities", and also evaluates "unproductive days" and "underproductive days." SDS assessments were conducted at the start of the open-label run-in period, at randomization, at week 4 , and every 12 weeks thereafter until week 52 (or until discontinuation).

\section{Statistical analyses}

\section{Acute studies}

Analyses were performed on the pooled modified intentto-treat population (patients who received study medication and had both a randomization and at least one post-randomization HAM-A total score). Missing data were imputed using the last observation carried forward methodology. Analysis of LSM changes from randomization in Q-LES-Q-SF percent maximum total score used an analysis of covariance model that included center as a random effect. The nonparametric Jonckheere-Terpstra test was used in an exploratory analysis of the pooled data to test if change from randomization in Q-LES-Q-SF percent maximum total score increased with increasing dose of quetiapine XR. In all cases, statistical tests were two-tailed with a significance level of 0.05 .

\section{Maintenance study}

Analyses were performed on the intent-to-treat population (patients who took study medication during the randomized treatment period). Analysis of LSM change from randomization to either an anxiety event or study end (defined as an anxiety event or any other reason for withdrawal) in
Q-LES-Q-SF percent maximum total, Q-LES-Q-SF percent items 15 and 16, PSQI global, and SDS total scores used an analysis of covariance model, with treatment and region as fixed effects. All assessments between randomization and up to but excluding the anxiety event were included in the analyses (patients were required to withdraw from the study after experiencing an anxiety event).

\section{Results \\ Patient population}

Acute studies

The patient populations for each of the three acute studies have been described previously. ${ }^{21-23}$ Only data from the quetiapine XR and placebo arms of the three studies were included in the pooled analysis; comparator drug arms were only included in the individual study analyses to allow for evaluation of assay sensitivity and risk/benefit analysis. In the pooled analysis, 2248 patients were included who had been randomly assigned to quetiapine XR $50 \mathrm{mg} /$ day $(\mathrm{n}=455), 150 \mathrm{mg} /$ day $(\mathrm{n}=678), 300 \mathrm{mg} /$ day $(\mathrm{n}=448)$, or placebo $(n=667)$; the modified intent-to-treat population included 2171 patients (63 patients had no valid HAM-A score at or after randomization). Overall quality of life, sleep quality, and overall functioning scores at baseline are shown in Table 1.

\section{Maintenance study}

The patient population for the maintenance study has been described previously. ${ }^{25}$ In total, 1248 patients were enrolled and 1224 patients were treated with quetiapine XR during the open-label period. Eight hundred and fifty patients entered the 12-18-week open-label stabilization period, with 433 patients randomized to receive quetiapine XR 50, 150 , or $300 \mathrm{mg} /$ day, or placebo (432 patients received study treatment). All patients who entered the randomized treatment period were randomly assigned either to continue quetiapine XR treatment $(n=216)$ at the same dose as prescribed at the last visit of the open-label stabilization period or to switch to placebo $(\mathrm{n}=216)$. The mean \pm standard deviation daily dose of quetiapine XR during randomized treatment was $162.8 \pm 88.3 \mathrm{mg} /$ day. Overall quality of life, sleep quality, and overall functioning scores at baseline are shown in Table 1.

\section{Patient-reported outcomes}

\section{Acute studies}

Quetiapine XR $150 \mathrm{mg} /$ day significantly improved the Q-LES-Q-SF percent maximum total score from randomization to week 8 (LSM change $11.90, P<0.001$ ) versus 
Table I Demographics and scores at randomization for HAM-A total and patient-reported outcome measures (pooled modified intent-to-treat population [acute studies] and intent-to-treat population [maintenance study])

\begin{tabular}{|c|c|c|c|c|c|c|}
\hline & \multicolumn{4}{|c|}{ Pooled acute studies $^{a}$} & \multicolumn{2}{|c|}{ Maintenance study } \\
\hline & $\begin{array}{l}\text { Placebo } \\
(n=654)\end{array}$ & $\begin{array}{l}\text { Quetiapine } \\
\text { XR } \\
50 \text { mg/day } \\
(n=438)\end{array}$ & $\begin{array}{l}\text { Quetiapine } \\
\text { XR } \\
\text { I50 mg/day } \\
(\mathrm{n}=654)\end{array}$ & $\begin{array}{l}\text { Quetiapine } \\
\text { XR } \\
300 \mathrm{mg} / \mathrm{day} \\
(\mathrm{n}=425)\end{array}$ & $\begin{array}{l}\text { Placebo }^{c} \\
(n=2 \mid 6)\end{array}$ & $\begin{array}{l}\text { Quetiapine } \\
X R^{d} \\
50-300 \mathrm{mg} / \text { day } \\
(\mathrm{n}=216)\end{array}$ \\
\hline \multicolumn{7}{|l|}{ Gender, n (\%) } \\
\hline Male & $236(36.1)$ & I64 (37.4) & $225(34.4)$ & $146(34.4)$ & $79(36.6)$ & $71(32.9)$ \\
\hline Female & $418(63.9)$ & $274(62.6)$ & $429(65.6)$ & $279(65.6)$ & 137 (63.4) & $145(67.1)$ \\
\hline \multicolumn{7}{|l|}{ Age, years } \\
\hline Mean \pm SD & $39.0 \pm 12.4$ & $39.9 \pm 11.7$ & $40.4 \pm 12.0$ & $40.0 \pm 12.3$ & $41.7 \pm 12.2$ & $44.8 \pm 11.0$ \\
\hline \multicolumn{7}{|c|}{ Time since first diagnosis of GAD, years } \\
\hline Mean $\pm S D$ & $4.8 \pm 6.8$ & $4.5 \pm 6.1$ & $4.5 \pm 6.0$ & $5.6 \pm 7.4$ & $5.3 \pm 7.8$ & $5.2 \pm 7.1$ \\
\hline \multicolumn{7}{|l|}{ Rating scale scores, mean (SD) } \\
\hline HAM-A total & $25.8 \pm 4.3$ & $25.8 \pm 4.2$ & $25.4 \pm 4.1$ & $24.8 \pm 3.7$ & $6.2 \pm 3.2$ & $5.9 \pm 3.3$ \\
\hline Q-LES-Q-SF \% maximum total & $51.0 \pm 15.4$ & $50.1 \pm 14.0$ & $51.1 \pm 14.8$ & $53.6 \pm 14.5$ & $68.2 \pm 14.3$ & $68.6 \pm 14.3$ \\
\hline $\begin{array}{l}\text { Q-LES-Q-SF \% item I5 } \\
\text { (satisfaction with medication) }\end{array}$ & $3.4 \pm 1.0$ & $3.4 \pm 0.9$ & $3.5 \pm 0.9$ & $3.7 \pm 0.9$ & $3.9 \pm 0.7$ & $4.1 \pm 0.6$ \\
\hline $\begin{array}{l}\text { Q-LES-Q-SF \% item I6 } \\
\text { (overall life satisfaction) }\end{array}$ & $2.8 \pm 0.9$ & $2.8 \pm 0.9$ & $2.8 \pm 0.9$ & $3.0 \pm 0.8$ & $3.7 \pm 0.8$ & $3.8 \pm 0.7$ \\
\hline PSQI global score & $11.0 \pm 3.7$ & $10.4 \pm 3.7$ & $10.7 \pm 3.8$ & $11.0 \pm 3.6$ & $5.3 \pm 3.5$ & $5.3 \pm 3.2$ \\
\hline Sleep quality & $1.9 \pm 0.8$ & $\mathrm{I} .8 \pm 0.7$ & $1.8 \pm 0.8$ & $1.9 \pm 0.8$ & $0.7 \pm 0.7$ & $0.6 \pm 0.6$ \\
\hline Sleep latency & $2.1 \pm 1.0$ & $2.0 \pm 1.0$ & $2.0 \pm 1.0$ & $2.1 \pm 1.0$ & $1.0 \pm 0.9$ & $1.0 \pm 0.9$ \\
\hline Sleep duration & $1.5 \pm 0.9$ & $1.3 \pm 0.9$ & $1.4 \pm 1.0$ & $1.5 \pm 1.0$ & $0.5 \pm 0.7$ & $0.6 \pm 0.7$ \\
\hline Habitual sleep efficiency & $1.4 \pm 1.3$ & $1.4 \pm 1.2$ & $1.4 \pm 1.3$ & $1.5 \pm 1.3$ & $0.7 \pm 1.2$ & $0.6 \pm 1.0$ \\
\hline Sleep disturbances & $1.8 \pm 0.6$ & $1.7 \pm 0.6$ & $1.7 \pm 0.6$ & $1.7 \pm 0.6$ & $\mathrm{I} . \mathrm{I} \pm 0.5$ & $1.2 \pm 0.5$ \\
\hline Use of sleep medication & $0.7 \pm 1.1$ & $0.6 \pm 1.0$ & $0.7 \pm \mathrm{I} . \mathrm{I}$ & $0.7 \pm 1.1$ & $0.3 \pm 0.9$ & $0.3 \pm 0.9$ \\
\hline Daytime dysfunction & $1.6 \pm 0.8$ & $1.6 \pm 0.8$ & $1.6 \pm 0.8$ & $1.6 \pm 0.8$ & $1.0 \pm 0.7$ & $0.9 \pm 0.7$ \\
\hline SDS total score & $\mathrm{NR}$ & NR & NR & NR & $6.4 \pm 6.2$ & $5.9 \pm 6.0$ \\
\hline Work/school & NR & NR & NR & NR & $2.2 \pm 2.1$ & $2.0 \pm 2.1$ \\
\hline Social life & NR & NR & NR & NR & $2.2 \pm 2.2$ & $1.9 \pm 2.1$ \\
\hline Family life/home responsibilities & NR & NR & NR & NR & $2.1 \pm 2.3$ & $2.0 \pm 2.1$ \\
\hline Unproductive days & NR & NR & NR & NR & $0.3 \pm 0.9$ & $0.2 \pm 0.8$ \\
\hline Underproductive days & NR & NR & NR & NR & $0.8 \pm 1.5$ & $0.7 \pm 1.4$ \\
\hline
\end{tabular}

Notes: aPooled acute studies, DI448C00009, DI448C00010, and DI448C000II; 'bmaintenance study, DI448C000I2; 'patients who received quetiapine XR in the open-label period and went on to receive placebo in the randomized period; ${ }^{d}$ patients who received quetiapine $X R$ in both the open-label and randomized periods.

Abbreviations: GAD, generalized anxiety disorder; HAM-A, Hamilton Rating Scale for Anxiety; NR, not recorded; PSQI, Pittsburgh Sleep Quality Index; Q-LES-Q-SF, Quality of Life and Satisfaction Questionnaire short form; SD, standard deviation; SDS, Sheehan Disability Scale; XR, extended release.

placebo (8.82); no significant difference was observed with quetiapine XR $50 \mathrm{mg}$ /day (LSM change 9.50, $P=0.461$ ) or $300 \mathrm{mg}$ /day (LSM change $8.15, P=0.473$, Figure $2 \mathrm{~A}$ ). The Jonckheere-Terpstra test did not reveal an increasing treatment effect with increasing dose of quetiapine XR (50, 150 , and $300 \mathrm{mg} /$ day) for the Q-LES-Q-SF percent maximum total scores $(12,14,12$, respectively, $P=0.513)$.

A small directional but nonsignificant improvement was observed in the Q-LES-Q-SF item 15 ("satisfaction with medication") score from randomization to week 8 for quetiapine XR $150 \mathrm{mg} /$ day (LSM change $0.03, P=0.742$ ) versus placebo $(-0.01)$; no difference was observed with quetiapine XR $50 \mathrm{mg}$ /day (LSM change $-0.14, P=0.377$ ), or $300 \mathrm{mg} /$ day (LSM change $-0.21, P=0.159$, Figure $2 \mathrm{~A}$ ).
Only a small number of patients had data reported for this item (quetiapine $\mathrm{XR}, \mathrm{n}=254$; placebo, $\mathrm{n}=105$ ).

A statistically significant improvement was observed in Q-LES-Q-SF item 16 (“overall life satisfaction”) scores from randomization to week 8 for quetiapine XR $50 \mathrm{mg} /$ day (LSM change $0.60, P=0.039$ ) and $150 \mathrm{mg} /$ day (LSM change 0.70 , $P<0.001)$ versus placebo (0.49); no significant difference was seen with quetiapine XR $300 \mathrm{mg} /$ day (LSM change 0.52 , $P=0.616$ ) versus placebo (Figure $2 \mathrm{~A}$ ).

Pooled PSQI global scores showed a significant improvement in sleep quality from randomization to week 8 for quetiapine XR $50 \mathrm{mg}$ /day (LSM change -5.00 , $P<0.001$ ), $150 \mathrm{mg} /$ day (LSM change $-5.25, P<0.001$ ), and $300 \mathrm{mg} /$ day (LSM change $-4.60, P<0.001$ ) versus 
A

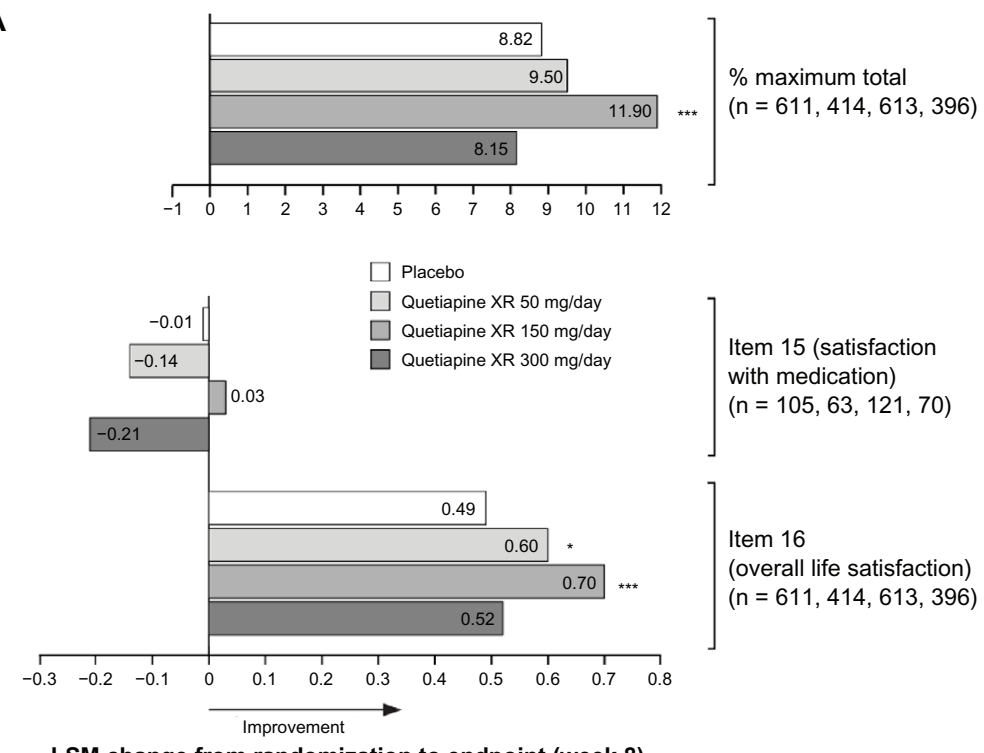

LSM change from randomization to endpoint (week 8)

B
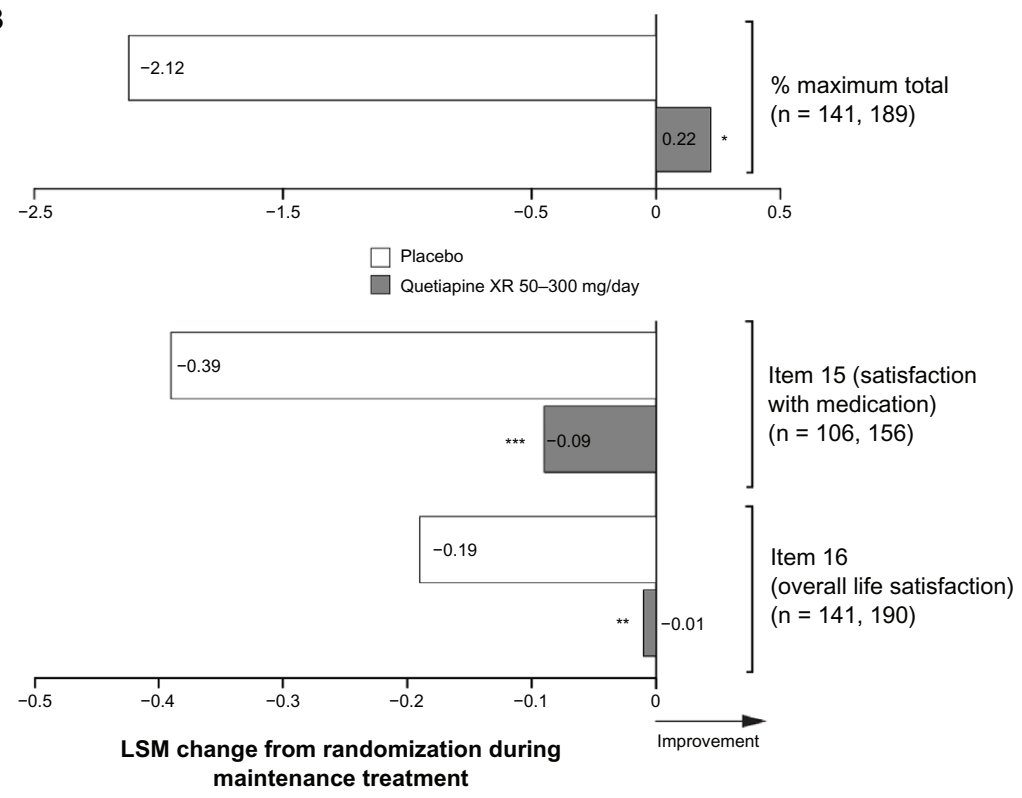

Figure 2 Least squares mean change from randomization in Quality of Life and Satisfaction Questionnaire short form scores at (A) week 8 in pooled acute studies (modified intent-to-treat; last observation carried forward) and (B) during randomized treatment in the maintenance study (intent-to-treat; last observation carried forward).

Notes: (A) $* P<0.05 ; * * * P<0.001$ vs placebo. $\mathrm{n}=$ placebo, quetiapine $X R 50,150$ and $300 \mathrm{mg} /$ day, respectively. (B) $* P<0.05 ; * * P<0.01 ; * * * P<0.001$ vs placebo. $\mathrm{n}=$ placebo and quetiapine $\mathrm{XR}$, respectively.

Abbreviations: ITT, intent-to-treat; LSM, least squares mean; XR, extended release.

placebo (-3.53, Figure 3A). With respect to PSQI individual items, there were significant improvements on six out of seven, five out of seven, and four out of seven item scores for quetiapine XR 50,150, and $300 \mathrm{mg}$ /day versus placebo, respectively (Figure 3A).

\section{Maintenance study}

Q-LES-Q-SF percent maximum total score improved from randomization only in the quetiapine XR group and was significantly better maintained during randomized treatment $(0.22, P<0.05)$ versus placebo $(-2.12)$. Improvement was also significantly better maintained in Q-LES-Q-SF items 15 (quetiapine $\mathrm{XR}-0.09, P<0.001$ versus placebo -0.39 ) and 16 (quetiapine $\mathrm{XR}-0.01, P<0.01$ versus placebo -0.19 ) scores (Figure 2B).

Quetiapine XR maintained significantly better overall sleep quality during randomized treatment, as shown by PSQI global scores $(0.39, P<0.001$ versus placebo 1.60$)$. 
A
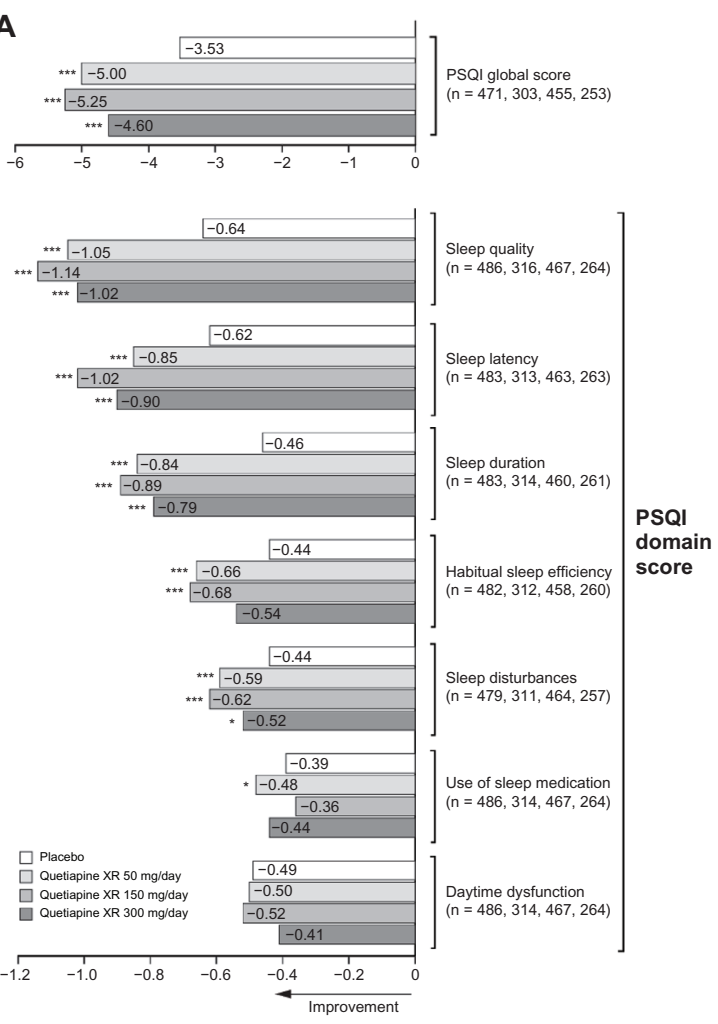

LSM change from randomization to endpoint (week 8)
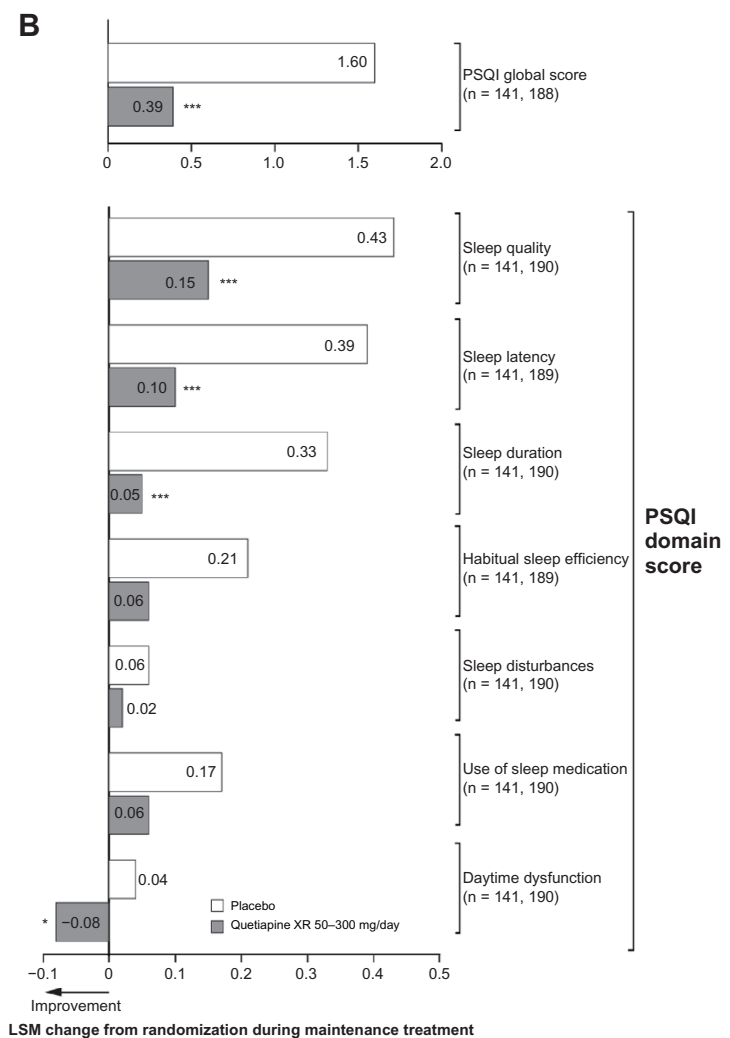

Figure 3 Least squares mean change from randomization in Pittsburgh Sleep Quality Index score at (A) week 8 in pooled acute studies (modified intentto-treat; last observation carried forward) and (B) during randomized treatment in the maintenance study (intent-to-treat; last observation carried forward).

Notes: $(\mathbf{A}) * P<0.05$; $* * * P<0.001$ vs placebo. $\mathrm{n}=$ placebo, quetiapine $\mathrm{XR} 50, \mathrm{I} 0$, and $300 \mathrm{mg} /$ day, respectively. (B) $* * * P<0.00 \mathrm{I}$ vs placebo. $\mathrm{n}=$ placebo, quetiapine $\mathrm{XR}$, respectively.

Abbreviations: ITT, intent-to-treat; LSM, least squares mean; PSQI, Pittsburgh Sleep Quality Index; XR, extended release.

Four of seven PSQI individual item scores were better maintained with quetiapine XR versus placebo (Figure 3B).

Quetiapine XR maintained a significantly better SDS total score during randomized treatment $(-0.19, P<0.05$ versus placebo 1.01), with significant improvements seen in "family life/home responsibilities" $(-0.13, P<0.05$ versus placebo 0.32$)$ and numerical improvements in "work/school" $(-0.10, P=0.051$ versus placebo 0.29$)$, and "social life" $(0.05, P=0.114$ versus placebo 0.34$)$. Patients treated with quetiapine XR had significantly fewer "unproductive days" from randomization to end of treatment $(-0.05, P<0.05)$ versus an increase with placebo $(0.11)$, and numerically fewer "underproductive days" $(0.06, P=0.619)$ versus placebo (0.13). Individual SDS item scores are shown in Figure 4.

\section{Discussion}

Results from the pooled analysis of the three acute studies have previously shown that quetiapine XR 50-300 mg/day is significantly effective at improving anxiety symptoms at week 1 and improvements continued until study end. ${ }^{26}$ In addition, data from the maintenance study have shown that these results are maintained over the long term. ${ }^{25}$ Beyond these rapid improvements in anxiety symptoms, the secondary analysis reported here suggests that quetiapine XR is effective at improving and maintaining improvements in quality of life, enjoyment and satisfaction, sleep quality, and overall functioning in patients with GAD.

Studies investigating the reliability, validity, and responsiveness of the Q-LES-Q-SF have identified significant correlations with clinical efficacy in patients with GAD, validating the use of this rating scale in this patient population. ${ }^{32}$ The data reported here show that quetiapine XR $150 \mathrm{mg} /$ day significantly improved health-related quality of life, as shown by changes in Q-LES-Q-SF percent maximum total score versus placebo in the pooled acute studies, and quetiapine $\mathrm{XR}$ 50-300 mg/day also better maintained improvements versus placebo in the long-term study. Quetiapine XR 50 and $150 \mathrm{mg} /$ day significantly improved patient "overall life satisfaction" (Q-LES-Q-SF item 16) versus placebo in the short term, and quetiapine XR 50-300 mg/day maintained significantly better improvements in patient "satisfaction with medication" (Q-LES-Q-SF item 15) and "overall life 

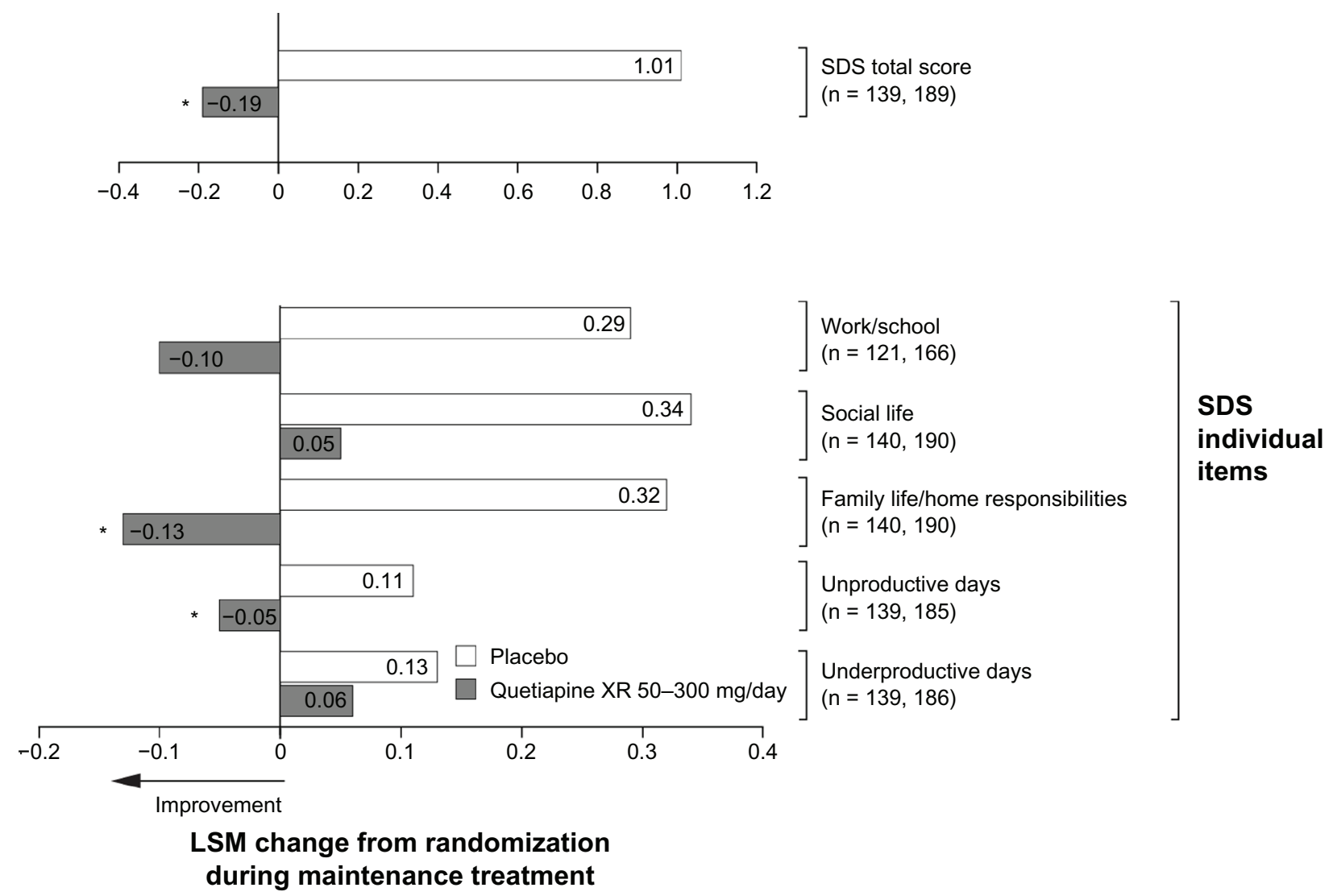

Figure 4 Least squares mean change from randomization in Sheehan Disability Scale score during randomized treatment in the maintenance study (intent-to-treat; last observation carried forward).

Notes: $* \mathrm{P}<0.05$ vs placebo. $\mathrm{n}=$ placebo and quetiapine $X R$, respectively.

Abbreviations: ITT, intent-to-treat; LSM, least squares mean; SDS, Sheehan Disability Scale; XR, extended release.

satisfaction" (Q-LES-Q-SF item 16) versus placebo during long-term therapy.

The significant improvement in health-related quality of life with quetiapine XR $150 \mathrm{mg} /$ day, but not quetiapine XR $50 \mathrm{mg} /$ day or $300 \mathrm{mg} /$ day, in the three acute studies appears to correspond with the improvements in HAM-A total score observed in the individual studies, as significant separation from placebo occurred with quetiapine XR $150 \mathrm{mg}$ /day consistently in all three studies. In addition, significance versus placebo was observed for quetiapine XR $50 \mathrm{mg} /$ day in study D1448C00009, $300 \mathrm{mg} /$ day in study D1448C000010, and $50 \mathrm{mg} /$ day in study D1448C000011. Significance versus placebo was not determined with quetiapine XR $300 \mathrm{mg} /$ day in study D1448C00009..$^{21-23}$ While the reasons for the lack of a dose-response relationship with quetiapine $\mathrm{XR}$ in this analysis remain speculative, one possible explanation is the increased withdrawal rate with quetiapine XR $300 \mathrm{mg}$ /day $(>35 \%$ ), due to reduced tolerability of this dose compared with lower doses. ${ }^{21-23,25}$

Previous short-term studies examining quality of life in patients with GAD receiving duloxetine and escitalopram have also reported improvements in Q-LES-Q-SF percent maximum total score with their current first-line treatments. ${ }^{11,33}$ Moreover, significant improvements in "overall satisfaction with medication" and "overall life satisfaction" scores measured by Q-LES-Q-SF were reported in an acute study of escitalopram in patients with GAD. ${ }^{12}$ Overall satisfaction with medication may help to improve adherence to a medication regimen, thereby expediting reduction in anxiety symptoms in patients with GAD. ${ }^{34}$ For patients with a chronic disorder, such as GAD, improvement in overall quality of life is pivotal because ongoing symptoms can have a detrimental effect on work, education, social environment, and health-related quality of life, ${ }^{5,6}$ therefore, improvement in overall quality of life may have far-reaching benefits for the patient.

Both quality and quantity of sleep are adversely affected among patients with GAD. Many clinicians believe that much of the insomnia reported by patients is actually a variant of $\mathrm{GAD}^{35}$ and that it can result in a significant reduction of quality of life and functioning. ${ }^{36}$ Insomnia associated with mild-to-moderate GAD generally responds well to psychological treatments and anxiolytic agents, with 
significant improvements in sleep quality reported with selective serotonin reuptake inhibitors, cyclopyrrolones, and benzodiazepines. ${ }^{37,38}$ Our analyses of PSQI scores in the acute and maintenance studies confirm that quetiapine $\mathrm{XR}$ is significantly more effective in improving and better maintaining quality of sleep in patients with GAD versus placebo. Significant changes were also seen for several items on the HAM-A psychic and somatic subscale scores, which demonstrate that the anxiolytic effect of quetiapine is broad and occurs independently of its effects on sleep. ${ }^{26}$

Findings from our pooled analysis of data from the acute studies are similar to those found in a short-term augmentation study, ${ }^{17}$ which showed that quetiapine significantly improved sleep quality in patients with GAD. Our pooled analysis confirms the findings from three individual acute studies that showed a significant improvement in PSQI global scores with quetiapine XR versus placebo. ${ }^{21-23}$

Patients with GAD have significantly impaired levels of functioning compared with healthy individuals, as assessed by SDS scores. ${ }^{39}$ The SDS total scores reported here show that quetiapine XR was significantly more effective in maintaining patient functioning compared with placebo; these data are consistent with other anxiolytic agents that have shown improvement in SDS total scores in acute studies of patients with GAD. ${ }^{40,41}$ By considering the individual domains of the SDS, the overall improvement in patient functioning was predominantly attributable to improvements in "family life/home responsibilities" and "work/school". Moreover, quetiapine XR-treated patients had fewer "unproductive days" and "underproductive days" at work compared with placebo. GAD is associated with a significant economic burden owing to decreased work productivity; ${ }^{1}$ one study reported $34 \%$ of patients with noncomorbid GAD showing a $10 \%$ reduction in work productivity and $11 \%$ of patients showing a $50 \%$ reduction in activity at work. ${ }^{5}$ The reduction in unproductive and underproductive days at work in patients treated with quetiapine $\mathrm{XR}$ reported here could therefore reduce the economic impact of GAD.

GAD places a substantial burden on the individual and is most notable in terms of diminished functioning in family life/home responsibilities, socially, and at work, ${ }^{1}$ with epidemiological studies describing impairment in these factors similar to that of major depression. ${ }^{42}$ In a European study of anxiety syndromes, $27 \%$ of patients with GAD reported moderate or severe social disability, rising to $59 \%$ when GAD was comorbid with major depression. ${ }^{43}$ The improvement and better maintenance of SDS domain scores versus placebo reported in our study is potentially of importance for functional status in patients with GAD.

Tolerability data, including the occurrence of extrapyramidal symptoms, have been reported previously for the individual studies ${ }^{21-23,25}$ and a pooled analysis of the acute studies. ${ }^{26}$ The overall tolerability profile of quetiapine XR was consistent with the known profile of quetiapine. ${ }^{44,45}$ Neither quetiapine XR nor quetiapine have regulatory approval for GAD in the United States or Europe.

Limitations of this analysis include the exclusion of patients with major depression or other anxiety disorders within 6 months of enrollment from participating in these studies because it has previously been reported that over $90 \%$ of patients with lifetime GAD have a lifetime mental or substance use disorder, with major depressive disorder being the most prevalent at $62.4 \% .{ }^{4}$ Therefore, our overall pooled population may not be clinically representative of patients encountered by physicians in day-to-day practice. It should also be noted that the three acute studies did not allow flexibility in quetiapine XR dosing; consequently, treatment is not reflective of clinical practice where the dose can be adjusted on the basis of the efficacy and tolerability in the individual patient. However, studies have shown quetiapine XR monotherapy to be effective in both acute ${ }^{46,47}$ and long-term maintenance treatment ${ }^{48}$ of major depressive disorder, the disorder that most frequently occurs as a comorbidity in patients with GAD. ${ }^{4}$

In conclusion, treatment with quetiapine XR 50$300 \mathrm{mg}$ /day monotherapy provided and maintained improvements in quality of life, sleep quality, and overall functioning compared with placebo during acute and maintenance treatment in patients with GAD.

\section{Disclosure}

These studies (Titanium, D1448C00009; Gold, D1448C00010; Silver, D1448C00011; Platinum, D1448C00012) were funded by AstraZeneca Pharmaceuticals. Sarah Lewis, from Complete Medical Communications, provided medical writing support funded by AstraZeneca. JE is an employee of the New York State Department of Mental Health and has received research support from the Department as well as the US National Institute of Mental Health, Cyberonics, and Pfizer. She has served as a consultant or advisory board member to AstraZeneca, Bayer, Cyberonics, Otsuka, Pfizer, and Wyeth-Ayerst. She is the author of the Quality of Life Enjoyment and Satisfaction Questionnaire. Henrik Svedsäter is a former employee of AstraZeneca. Julie Locklear is a current employee of AstraZeneca. 


\section{References}

1. Wittchen HU. Generalized anxiety disorder: prevalence, burden, and cost to society. Depress Anxiety. 2002;16(4):162-171.

2. Carter RM, Wittchen HU, Pfister H, Kessler RC. One-year prevalence of subthreshold and threshold DSM-IV generalized anxiety disorder in a nationally representative sample. Depress Anxiety. 2001;13(2): $78-88$.

3. Jacobi F, Wittchen HU, Holting C, et al. Prevalence, co-morbidity and correlates of mental disorders in the general population: results from the German Health Interview and Examination Survey (GHS). Psychol Med. 2004;34(4):597-611.

4. Wittchen HU, Zhao S, Kessler RC, Eaton WW. DSM-III-R generalized anxiety disorder in the National Comorbidity Survey. Arch Gen Psychiatry. 1994;51(5):355-364.

5. Wittchen HU, Carter RM, Pfister H, Montgomery SA, Kessler RC. Disabilities and quality of life in pure and comorbid generalized anxiety disorder and major depression in a national survey. Int Clin Psychopharmacol. 2000;15(6):319-328.

6. Massion AO, Warshaw MG, Keller MB. Quality of life and psychiatric morbidity in panic disorder and generalized anxiety disorder. $\mathrm{Am} \mathrm{J}$ Psychiatry. 1993;150(4):600-607.

7. Yonkers KA, Dyck IR, Warshaw M, Keller MB. Factors predicting the clinical course of generalised anxiety disorder. Br J Psychiatry. 2000;176:544-549.

8. Ballenger JC, Davidson JRT, Lecrubier Y, et al. Consensus statement on generalized anxiety disorder from the International Consensus Group on Depression and Anxiety. J Clin Psychiatry. 2001; 62 Suppl 11:53-58.

9. Rogers MP, Warshaw MG, Goisman RM, et al. Comparing primary and secondary generalized anxiety disorder in a long-term naturalistic study of anxiety disorders. Depress Anxiety. 1999;10(1):1-7.

10. Bandelow B, Zohar J, Hollander E, Kasper S, Moller HJ. World Federation of Societies of Biological Psychiatry (WFSBP) guidelines for the pharmacological treatment of anxiety, obsessive-compulsive and post-traumatic stress disorders - First revision. World J Biol Psychiatry. 2008;9(4):248-312.

11. Pollack MH, Endicott J, Liebowitz M, et al. Examining quality of life in patients with generalized anxiety disorder: clinical relevance and response to duloxetine treatment. $J$ Psychiatr Res. 2008;42(12): 1042-1049.

12. Demyttenaere K, Andersen HF, Reines EH. Impact of escitalopram treatment on Quality of Life Enjoyment and Satisfaction Questionnaire scores in major depressive disorder and generalized anxiety disorder. Int Clin Psychopharmacol. 2008;23(5):276-286.

13. Monti JM, Monti D. Sleep disturbance in generalized anxiety disorder and its treatment. Sleep Med Rev. 2000;4(3):263-276.

14. Mullen J, Jibson MD, Sweitzer D. A comparison of the relative safety, efficacy, and tolerability of quetiapine and risperidone in outpatients with schizophrenia and other psychotic disorders: the quetiapine experience with safety and tolerability (QUEST) study. Clin Ther. 2001;23(11):1839-1854.

15. Calabrese JR, Keck PE Jr, MacFadden W, et al. A randomized, double-blind, placebo-controlled trial of quetiapine in the treatment of bipolar I or II depression. Am J Psychiatry. 2005;162(7): 1351-1360.

16. Thase ME, MacFadden W, Weisler RH, et al. Efficacy of quetiapine monotherapy in bipolar I and II depression: a double-blind, placebocontrolled study (the BOLDER II study). J Clin Psychopharmacol. 2006;26(6):600-609.

17. Katzman MA, Vermani M, Jacobs L, et al. Quetiapine as an adjunctive pharmacotherapy for the treatment of non-remitting generalized anxiety disorder: a flexible-dose, open-label pilot trial. JAnxiety Disord. 2008;22(8):1480-1486.

18. Endicott J, Paulsson B, Gustafsson U, Schioler H, Hassan M. Quetiapine monotherapy in the treatment of depressive episodes of bipolar I and II disorder: improvements in quality of life and quality of sleep. $J$ Affect Disord. 2008;111(2-3):306-319.
19. Datto C, Berggren L, Patel JB, Eriksson H. Self-reported sedation profile of immediate-release quetiapine fumarate compared with extended-release quetiapine fumarate during dose initiation: a randomized, double-blind, crossover study in healthy adult subjects. Clin Ther. 2009;31(3):492-502.

20. Kahn RS, Schulz SC, Palazov VD, et al. Efficacy and tolerability of once-daily extended release quetiapine fumarate in acute schizophrenia: a randomized, double-blind, placebo-controlled study. J Clin Psychiatry. 2007;68(6):832-842.

21. Khan A, Joyce M, Atkinson S, Eggens I, Baldytcheva I, Eriksson H. A randomized, double-blind study of once-daily extended release quetiapine fumarate (quetiapine XR) monotherapy in patients with generalized anxiety disorder. J Clin Psychopharmacol. 2011;31(4):418-428.

22. Merideth C, Cutler AJ, She F, Eriksson H. Efficacy and tolerability of extended release quetiapine fumarate monotherapy in the acute treatment of generalized anxiety disorder: a randomized, placebo controlled and active-controlled study. Int Clin Psychopharmacol. 2012; 27(1):40-54.

23. Bandelow B, Chouinard G, Bobes J, et al. Extended-release quetiapine fumarate (quetiapine XR): a once-daily monotherapy effective in generalized anxiety disorder. Data from a randomized, double-blind, placebo- and active-controlled study. Int $J$ Neuropsychopharmacol. 2010;13(3):305-320.

24. Magi K, Mezhebovsky I, She F, Datto C, Eriksson HA. Efficacy and tolerability of extended release quetiapine fumarate (quetiapine XR) monotherapy in elderly patients with generalised anxiety disorder (GAD). World J Biol Psychiatry. 2009;10:239.

25. Katzman MA, Brawman-Mintzer O, Reyes EB, Olausson B, Liu S, Eriksson $\mathrm{H}$. Extended release quetiapine fumarate (quetiapine XR) monotherapy as maintenance treatment for generalized anxiety disorder: a long-term, randomized, placebo-controlled trial. Int Clin Psychopharmacol. 2011;26(1):11-24.

26. Stein DJ, Bandelow B, Merideth C, Olausson B, Szamosi J, Eriksson H. Efficacy and tolerability of extended release quetiapine fumarate (quetiapine XR) monotherapy in patients with generalised anxiety disorder: an analysis of pooled data from three 8-week placebocontrolled studies. Hum Psychopharmacol. 2011;26(8):614-628.

27. American Psychiatric Association. Diagnostic and Statistical Manual of Mental Disorders, Fourth Edition, Text Revision. Washington, DC: American Psychiatric Association; 2000.

28. Sheehan DV, Lecrubier Y, Sheehan KH, et al. The Mini-International Neuropsychiatric Interview (MINI): the development and validation of a structured diagnostic psychiatric interview for DSM-IV and ICD-10. J Clin Psychiatry. 1998;59 Suppl 20:22-33.

29. Endicott J, Nee J, Harrison W, Blumenthal R. Quality of Life Enjoyment and Satisfaction Questionnaire: a new measure. Psychopharmacol Bull. 1993;29(2):321-326.

30. Buysse DJ, Reynolds CF III, Monk TH, Berman SR, Kupfer DJ. The Pittsburgh Sleep Quality Index: a new instrument for psychiatric practice and research. Psychiatry Res. 1989;28(2):193-213.

31. Sheehan DV. The Anxiety Disease. New York, NY: Scribner; 1996.

32. Wyrwich K, Harnam N, Revicki DA, Locklear JC, Svedsater H, Endicott J. Assessing health-related quality of life in generalized anxiety disorder using the Quality Of Life Enjoyment and Satisfaction Questionnaire. Int Clin Psychopharmacol. 2009;24(6):289-295.

33. Endicott J, Russell JM, Raskin J, et al. Duloxetine treatment for role functioning improvement in generalized anxiety disorder: three independent studies. J Clin Psychiatry. 2007;68(4):518-524.

34. den Boer JA, Evans DL, Lee S, Salin-Pascual R. Unraveling the diagnostic clues of depression and GAD: the primary care challenge. Psychopharmacol Bull. 2002;36 Suppl 2:150-157.

35. Nutt D, Argyropoulos S, Hood S, Potokar J. Generalized anxiety disorder: a comorbid disease. Eur Neuropsychopharmacol. 2006; 16 Supp1 2:S109-S118.

36. Belanger L, Morin CM, Langlois F, Ladouceur R. Insomnia and generalized anxiety disorder: effects of cognitive behavior therapy for gad on insomnia symptoms. J Anxiety Disord. 2004;18(4):561-571. 
37. Rosenthal M. Tiagabine for the treatment of generalized anxiety disorder: a randomized, open-label, clinical trial with paroxetine as a positive control. J Clin Psychiatry. 2003;64(10):1245-1249.

38. Fontaine R, Beaudry P, Le Morvan P, Beauclair L, Chouinard G. Zopiclone and triazolam in insomnia associated with generalized anxiety disorder: a placebo-controlled evaluation of efficacy and daytime anxiety. Int Clin Psychopharmacol. 1990;5(3):173-183.

39. Kennedy BL, Lin Y, Schwab JJ. Work, social, and family disabilities of subjects with anxiety and depression. South Med J. 2002;95(12): 1424-1427.

40. Pollack MH, Zaninelli R, Goddard A, et al. Paroxetine in the treatment of generalized anxiety disorder: results of a placebo-controlled, flexibledosage trial. J Clin Psychiatry. 2001;62(5):350-357.

41. Rynn M, Russell J, Erickson J, et al. Efficacy and safety of duloxetine in the treatment of generalized anxiety disorder: a flexible-dose, progressive-titration, placebo-controlled trial. Depress Anxiety. 2008; 25(3):182-189.

42. Kessler RC, Keller MB, Wittchen HU. The epidemiology of generalized anxiety disorder. Psychiatr Clin North Am. 2001;24(1):19-39.

43. Weiller E, Bisserbe JC, Maier W, Lecrubier Y. Prevalence and recognition of anxiety syndromes in five European primary care settings. A report from the WHO study on Psychological Problems in General Health Care. Br J Psychiatry. 1998;173 Suppl 34:18-23.
44. AstraZeneca. Seroquel XR - Summary of product characteristics for Ireland. Available from: http://www.medicines.ie/medicine/ $13032 / \mathrm{SPC} / \mathrm{Seroque} 1+\mathrm{XR}+50 \mathrm{mg} \% 2 \mathrm{c}+150 \mathrm{mg} \% 2 \mathrm{c}+200 \mathrm{mg}$ $\% 2 \mathrm{c}+300 \mathrm{mg} \% 2 \mathrm{c}+400 \mathrm{mg}+$ prolonged-release+tablets/. Accessed May 24, 2012.

45. AstraZeneca. Seroquel XR (quetiapine fumarate) extended-release tablets/US prescribing information. Available from: http://www1. astrazeneca-us.com/pi/seroquelxr.pdf. Accessed May 24, 2012.

46. Cutler AJ, Montgomery SA, Feifel D, Lazarus A, Åström M, Brecher M. Extended release quetiapine fumarate monotherapy in major depressive disorder: a placebo- and duloxetine-controlled study. J Clin Psychiatry. 2009;70(4):526-539.

47. Weisler R, Joyce M, McGill L, Lazarus A, Szamosi J, Eriksson H. Extended release quetiapine fumarate monotherapy for major depressive disorder: results of a double-blind, randomized, placebo-controlled study. CNS Spectr. 2009;14(6):299-313.

48. Liebowitz M, Lam RW, Lepola U, Datto C, Sweitzer D, Eriksson H. Efficacy and tolerability of extended release quetiapine fumarate monotherapy as maintenance treatment of major depressive disorder: a randomized, placebo-controlled trial. Depress Anxiety. 2010;27(10): 964-976.
Neuropsychiatric Disease and Treatment

\section{Publish your work in this journal}

Neuropsychiatric Disease and Treatment is an international, peerreviewed journal of clinical therapeutics and pharmacology focusing on concise rapid reporting of clinical or pre-clinical studies on a range of neuropsychiatric and neurological disorders. This journa is indexed on PubMed Central, the 'PsycINFO' database and CAS

\section{Dovepress}

The manuscript management system is completely online and includes a very quick and fair peer-review system, which is all easy to use. Visit http://www.dovepress.com/testimonials.php to read real quotes from published authors. 